\title{
Reação alérgica ao azul patente
}

\author{
Hospital Nove de Julho, São Paulo
}

INTRRDUCॄÃa

Os linfonodos sentinelas são localizados ao se usar tintura de azul patente e colóide Tecnesium radiopaco. A excisão do linfonodo sentinela é um tratamento para estadiamento no câncer em cirurgias oncológicas de mama (mais comum), pele e abdominais. Reaçôes alérgicas são descritas desde a década de 60 . Alteração da oximetria de pulso, em função da interferência na leitura do comprimento de onda, utilizado para medir a oxihemoglobina, também tem sido descrita.

\section{RELATI DO CASD}

Paciente feminina, 41 anos, estado físico P2 (antigo ASA II), com história de alergia à dipirona, AINH e sulfa. Cirurgias anteriores: cesária e nódulo de mama direita, sem intercorrências. Indicada setorectomia de mama bilateral com pesquisa de linfonodo sentinela bilateral. Após monitorização, recebeu anestesia geral com: $\mathrm{O}_{2}, \mathrm{~N}_{2} \mathrm{O}$, fentanila, lidocaína, propofol e remifentanil (alvo-controlados) e cisatracurium. Depois de 15 minutos da injeção de azul patente, a paciente apresentou perda da oximetria de pulso inicialmente, e depois hipotensão com taquicardia. Observado nesse instante rush cutâneo, que permaneceu o tempo todo da anestesia. Então foram interrompidos o propofol e o remifentanil, e iniciados sevorane e norcurônio de curare, além de medidas de suporte: etilefrina em bolus, hidratação (3,5 l), hidrocortisona. Após 2 horas do início dos sintomas, com o fim da cirurgia, a pressão voltou a subir, atingindo níveis normais ao final de 150 minutos da injeção de azul patente. A paciente foi descurarizada com atropina, neostigmine e furosemida, e encaminhada à recuperação anestésica (RA). Devido à persistência de placas eritematosas em tronco, pescoço e face, a paciente foi encaminhada à UTI, onde permaneceu por dois dias. Recebeu alta hospitalar no sexto dia pós-operatório.

DISடบรSÃロ

As reaçôes do tipo alérgico ao azul patente apresentam graus variados de gravidade, desde diminuição da oximetria de pulso, manifestações cutâneas, até choque anafilático. Em nosso caso, isso poderia ter sido evitado fazendo-se o teste cutâneo prévio ou com nova abordagem usando azul de metileno nessa técnica, ou ainda evitando seu uso devido à alergia a sulfa.

REFERÊNCIAS

Mullan MH, Deacock SJ, Quiney NF, Kissin MW. Anaphylaxis to patent blue dye during sentinellymph node biopsy for breast cancer. Eur J Surg Oncol. 2001;27(2):218-9.

2. Hoskin RW, Granger R. Intraoperative decrease in pulse oximeter readings following injection of isosulfan blue. Can J Anesth. 2001;48:38-40.

Endereço para correspondência: Emilio C. Del Massa

R. Peixoto Gomide, 235

São Paulo (SP) - CEP $01409-902$

Tel. (+55 11) 3147-9658 / 9970-2446

E-mail: delmassa@ig.com.br 